\title{
INCORPORATING PTGF-ק1/CALCIUM PHOSPHATE NANOPARTICLES WITH FIBRONECTIN INTO 3-DIMENSIONAL COLLAGEN/CHITOSAN SCAFFOLDS: EFFICIENT, SUSTAINED GENE DELIVERY TO STEM CELLS FOR CHONDROGENIC DIFFERENTIATION
}

\author{
Xia Cao§, Wenwen Deng§, Yuan Wei§, Yan Yang§, Weiyan Su, Yawei Wei, Ximing Xu* and Jiangnan Yu*
}

Department of Pharmaceutics, School of Pharmacy, and Center for Drug/Gene Delivery and Tissue Engineering, Jiangsu University, Zhenjiang, R.P. China.

$\S$ These authors contributed equally to this work.

\begin{abstract}
The objective of this study was to prepare a 3-dimensional nanoparticle gene delivery system (3D-NGDS) based on collagen/chitosan scaffolds, in which plasmid transforming growth factor beta 1 (TGF- $\beta 1$ )/calcium phosphate nanoparticles mixed with fibronectin (FN) were used to transfect mesenchymal stem cells (MSCs). Scanning electron microscopy was used to characterise the microstructure of 3-dimensional collagen/chitosan scaffolds. An analysis performed to quantify the TGF- $\beta 1$ concentrations in MSC cultures revealed that the MSCs transfected with the 3D-NGDS showed remarkably high levels of TGF- $\beta 1$ over long periods, retaining a concentration of TGF- $\beta 1$ of approximately $10 \mathrm{ng} / \mathrm{mL}$ within two weeks, with the highest level $(12.6 \mathrm{ng} / \mathrm{mL})$ being observed on the 6th day. An immunohistochemistry analysis for collagen type II revealed that much higher production of collagen II from the 9th to 15 th day was observed in the 3D-NGDS-transfected MSCs than that in MSCs transfected by the Lipofectamine 2000 method. The glycosaminoglycan content of the 3D-NGDS was comparable to those treated with TGF- $\beta 1$ as well as TGF- $\beta 1$ plus dexamethasone, and was significantly higher than those treated with free plasmid and Lipofectamine 2000. A remarkable type I collagen expression inhibition of the 3D-NGDS at day 21 was observed via ELISA. These results suggested that transfection with the 3D-NGDS could successfully induce MSC chondrogenic differentiation in vitro without dexamethasone. In summary, the 3D-NGDS could be developed into a promising alternative method to transfer exogenous nucleic acid to MSCs in clinical trials.
\end{abstract}

Keywords: collagen, chitosan, calcium phosphate nanoparticles, gene transfer, nonviral gene delivery, fibronectin, mesenchymal stem cells, three dimensional scaffolds.

* Address for Correspondance:

Ximing $\mathrm{Xu}$

Department of Pharmaceutics, School of Pharmacy

Jiangsu University

301 Xuefu Road, Jingkou District

Zhenjiang 212001, R.P. China.

Tel/Fax: +86-511-85038451

Email: xmxu@ujs.edu.cn

Alternatively: Jiangnan Yu

E-mail: yjn@ujs.edu.cn
Introduction

Tissue engineering has emerged as an exciting research area aiming at the development of biological substitutes that restore, maintain, or improve tissue function (Ma, 2008; Sachlos and Czernuszka, 2009). A typical tissue engineering approach consists of an interactive triad of a supportive matrix, responsive cells and bioactive molecules promoting differentiation and regeneration. A highly porous three dimensional (3D) scaffold with good properties is critical to control tissue formation in tissue engineering. Compared with the 2D surfaces, such as cell culture flasks or plates, 3D scaffolds can provide more available surface area for cell attachment and spreading, simulate in vivo microenvironment for cell proliferation and differentiation, and govern gene expression in a way that correlates well with that of in vivo gene expression (Saraf et al., 2010). Tissue engineering scaffolds have played a role in providing the required local microenvironment for regenerative cells, supporting cell attachment, proliferation, and differentiation, in addition to the structural properties that create and maintain space for tissue growth (Zhang et al., 2006).

A biodegradable matrix containing plasmid DNA was first called a "gene-activated matrix" (GAM) (Fang et al., 1996; Bonadio et al., 1998). In the field of tissue engineering and regenerative medicine, delivering plasmid DNA encoding for various growth factors, signalling molecules and bioactive molecules to cells has more advantages than does continuously injecting cytokines because proteins are not as stable as DNA (Bonadio et al., 1998). Proteins may denature and lose their functionality, while DNA will retain its structural and functional integrity in many solvents, making DNA compatible with a wider range of scaffold preparation methods. Additionally, the intracellular expression of the delivered plasmids can be sustained over a period of days so as to mitigate the drawbacks of the short half-lives of most biological factors (Aviles et al., 2010; Bonadio et al., 1999; Saraf et al., 2010). The sustained release of plasmids can be modulated by controlling the scaffold processing parameters or adopting such methods as microsphere encapsulation (Jang and Shea, 2006), microparticle or nanoparticle incorporation (Luu et al., 2003), and layerby-layer assemblies with cationic polymers (Jewell and Lynn, 2008).

To date, a number of biomaterials have been explored for various tissue engineering scaffolds, ranging from synthetic materials such as polylactic acid and 
polyglycolic acid (PLGA) copolymers, polylactic acidpolyethylene glycol (PLA-PEG) block copolymers (Luu et al., 2003), polycaprolactone, poly-hydroxybutyrate and polyethylene terephthalate (Tang and $\mathrm{Wu}, 2006$ ), to natural polymers such as collagen (Yow et al., 2009; Sun et al., 2009), chitosan (Suh and Matthew, 2000), fibrin (Saul et al., 2007), fibroin (Garcia-Fuentes et al., 2009), hyaluronan (HA) (Hemmrich et al., 2005) and so on. Natural scaffolds are functionally superior to noninformational synthetic polymers because they provide an extracellular matrix and informational signalling molecules such as gelatin, collagen, and glycosaminoglycan (GAG). Collagen is a widely used natural polymer that contains both acidic and basic amino acid residues (Samuel et al., 2002; Tan et al., 2001) and exists in many tissues and organs. Chitosan is a natural polysaccharide derived from the partial deacetylation of chitin, and has been reported to be nontoxic, biocompatible, biodegradable and non-antigenic, which has led it to become an attractive candidate for cartilage tissue engineering (Suh and Matthew, 2000; Xu et al., 2008b). Moreover, the polysaccharide backbone of chitosan is structurally similar to that of glycosaminoglycan, a major component of the extracellular matrix (ECM) of bone and cartilage. One of the most interesting features of chitosan is its cationic nature due to the primary amine groups that provide a high positive charge density in an acidic solution, which allows for an easy combination with negatively charged polymers such as collagen. The exclusive use of any of these two materials has limitations owing to their own inherently poor mechanical properties (Suh and Matthew, 2000; Yow et al., 2009). Thus, combined use of chitosan and collagen is a better strategy for scaffold construction. The applications of porous chitosan/collagen scaffolds in tissue engineering have been widely reported (Tan et al., 2001; Peng et al., 2006). In our present study, fibronectin (FN) was used to fabricate porous chitosan/collagen scaffolds because it is one of the ECM components of articular cartilage, which contains the amino acid sequence Arg-Gly-Asp (RGD) (Sottile et al., 2000), a widely occurring cell adhesive motif originally discovered in FN. It is reported that each subunit of FN is composed of three different components, designated type I, II and III modules. These modules comprise various functional domains from the $\mathrm{N}$-terminus (Hang et al., 2005), which are relatively resistant to proteases and contain the binding sites for macromolecules such as collagen, fibrinogen, fibrin, and proteoglycans, as well as cells (Kaspar et al., 2006).

To achieve the goal of tissue regeneration, various growth factors have generally been introduced into tissue-engineered systems to improve tissue-forming efficiency. For instance, platelet-derived growth factor (PDGF) (Hafeman et al., 2010; Johnson et al., 2010), transforming growth factor beta-1 (TGF-ß1) (Lee et al., 2004) insulin-like growth factor (IGF) (Xu et al., 2008a; Wang et al., 2009), vascular endothelial growth factor (VEGF) (Mao et al., 2009; Kanczler et al., 2008), and fibroblast growth factor (FGF) (Briganti et al., 2010) have recently been widely employed in regenerative medicine and tissue engineering. TGF- $\beta 1$, a member of the cytokine family, possesses multifunctional capacities that regulate many aspects of cellular activity, including cell proliferation, differentiation, and extracellular matrix (ECM) metabolism, in a time- and concentrationdependent manner (Elisseeff et al., 2001). Previous studies have reported that TGF- $\beta 1$-loaded scaffolds may enhance cartilage formation (Lee et al., 2004; Guo et al., 2006). Because traumatic injuries or contracting degenerative joint diseases have gained prevalence worldwide and articular cartilage has a limited capacity for regeneration or repair, which may cause serious suffering and inconvenience, there is a need to find a highly efficient and feasible therapy apart from conventional surgery. Thus, our group used TGF- $\beta 1$ to stimulate cartilage tissue formation.

Calcium phosphate is a commonly used gene transfection agent in non-viral gene delivery because $\mathrm{Ca}^{2+}$ can form ionic complexes with phosphates on the nucleic acid backbone of plasmid DNA by the electrostatic interaction between the positively charged $\mathrm{Ca}^{2+}$ and the negatively charged nucleic acid (Keeney et al., 2010; Roohani-Esfahani et al., 2010). Following the methods of previous studies, we prepared plasmid DNA/calcium phosphate nanoparticles (CP-pDNA-NPs) by incorporating negative plasmid DNA-encoding TGF- $\beta 1$ into calcium phosphate nanoparticles. CP-pDNA-NPs were then mixed with FN and loaded into collagen/chitosan scaffolds to construct a 3D nanoparticle gene delivery system (3D-NGDS). The objective of this work is to report a novel non-viral, long-term gene delivery system with high transfection efficiency for tissue engineering.

\section{Materials and Methods}

\section{Chemicals and materials}

Chitosan (Deacetylation Degree $>95 \%$, MW $<5000$ $\mathrm{kDa}$ ) was obtained from Marine Biotech Ltd. (Zhejiang, China). Murine collagen was obtained from TianXinFu Medical Appliance Co. Ltd. (Beijing, China). Dulbecco's Modified Eagle's Medium (DMEM), fetal bovine serum (FBS), penicillin-streptomycin, trypsin-EDTA $(0.25 \%$ trypsin/0.02 \% EDTA) in Hank's buffered salt solution, PicoGreen dsDNA Quantitation kit, and calcium/ magnesium-free phosphate-buffered saline (PBS) were obtained from Gibco-Invitrogen (Grand Island, NY, USA). Rat TGF- $\beta 1$ plasmid was generously provided by Dr. Guang-Jian Zhang of the Medical College of Wisconsin (Milwaukee, WI, USA). Purified TGF- $\beta 1$ plasmid was prepared using a Pure Yield Plasmid Midiprep Kit (Promega, Madison, WI, USA). A Rat TGF- $\beta 1$ ELISA Kit was purchased from Yantai Science and Biotechnology Co. Ltd. (Shandong, China). Papain, chondroitin-4-sulphate dilution, dexamethasone (Dex) and DL-dithiothreitol (DTT) were purchased from Sigma-Aldrich (St. Louis, MO, USA).

The experimental protocol was approved by the University Ethics Committee for the Use of Experimental Animals and conformed to the Guide for Care and Use of Laboratory Animals. 


\section{Preparation of collagen/chitosan scaffolds}

Two-percent (w/v) chitosan and collagen solutions were prepared separately in $1 \%(\mathrm{v} / \mathrm{v})$ acetic acid solvent at 37 ${ }^{\circ} \mathrm{C}$. Homogeneous mixture solutions with different weight ratios of chitosan/collagen $(10: 1,5: 1,2: 1,1: 1,1: 2,5: 1)$ were transferred into 6 -well plates. The 6 -well plates were left in vacuum for $3 \mathrm{~h}$ at room temperature for soluble gas removal. The plates were then cooled at $4{ }^{\circ} \mathrm{C}$ for $30 \mathrm{~min}$ and rapidly transferred into a $-20^{\circ} \mathrm{C}$ freezer and kept overnight. The next day, the chitosan and collagen mixtures were lyophilised at $-80^{\circ} \mathrm{C}$ for $48 \mathrm{~h}$ until they were completely dried. The resulting scaffolds (area $2 \mathrm{~cm}^{2}$, thickness 3.0 $\mathrm{mm}$ ) were neutralised in $0.3 \mathrm{M} \mathrm{NaOH}$ and washed in double-distilled water until the $\mathrm{pH}$ of the last washing solution reached 7.4. The neutralised scaffolds were lyophilised again and baked in an oven at a temperature of $120^{\circ} \mathrm{C}$ overnight for fixation and sterilisation.

The water-uptake and water-retention abilities of the scaffolds were determined as follows. Dry scaffolds were weighed $(\mathrm{Wd})$, immersed in distilled water for 24 $\mathrm{h}$, gently blotted with filter paper to remove the excess water, and weighed $(\mathrm{Ww})$ to determine water uptake. To measure the water-retention capability, the wet scaffolds were transferred to centrifuge tubes with filter paper at the bottom, centrifuged at $500 \mathrm{rpm}$ for $3 \mathrm{~min}$ and weighed immediately (Wrw). The water absorption rate $\left(\mathrm{R}_{\mathrm{ab}}\right)$ as well as water retention rate $\left(\mathrm{R}_{\text {ret }}\right)$ of the scaffolds at equilibrium were calculated using equations (1) and (2).

$$
\begin{aligned}
& \mathrm{R}_{\mathrm{ab}}(\%)=[(\mathrm{Ww}-\mathrm{Wd}) / \mathrm{Wd}] \times 100 \\
& \mathrm{R}_{\mathrm{ret}}(\%)=[(\mathrm{Wrw}-\mathrm{Wd}) / \mathrm{Wd}] \times 100
\end{aligned}
$$

\section{Preparation of plasmid TGF- $\beta 1$}

The plasmid TGF- $\beta 1$ was amplified in Escherichia coli host stain DH $5 \alpha$ and purified by column chromatography with the PureYield ${ }^{\text {TM }}$ Plasmid Maxiprep Start-Up Kit (Promega, Madison, Wisconsin, USA) according to the manufacturer's protocol. Ampicilin was used to select plasmid TGF- $\beta 1$ (pTGF- $\beta 1$ )-transformed cells. The DNA concentration was detected by measuring the UV absorbance at $260 \mathrm{~nm}$ with an ultraviolet spectrophotometer. UV spectroscopy showed that the A260/A280 absorbance was between 1.8 and 1.9, which indicated that no protein or RNA was present. The detail information regarding the structure of plasmid TGF- $\beta 1$ is shown in Fig. 1.

\section{Preparation of the 3-dimensional nanoparticle gene delivery system (3D-NGDS)}

To complete the 3D-NGDS, CP-pDNA-NPs (calcium phosphate nanoparticles encapsulating plasmid TGF- $\beta 1$ ) and FN were incorporated into collagen/chitosan scaffolds. The preparation of CP-pDNA-NPs was performed according to an established method (Morgan et al., 2008) using plasmid TGF- $\beta 1$ in place of negatively charged dyes. The CP-pDNA-NPs were spherical and well-dispersed with an average size of approximately $20 \mathrm{~nm}$ (data not shown). 2 $\mathrm{mL}$ sterilised PBS, pH 7.4, containing CP-pDNA-NPs and fibronectin was filtered and loaded onto the dry collagen/ chitosan scaffolds. $2 \mathrm{mg}$ plasmid DNA and $1 \mu \mathrm{g}$ FN were used per mg of scaffold. The loaded scaffolds were kept at $4{ }^{\circ} \mathrm{C}$ overnight for the full incorporation of CP-pDNA-NPs

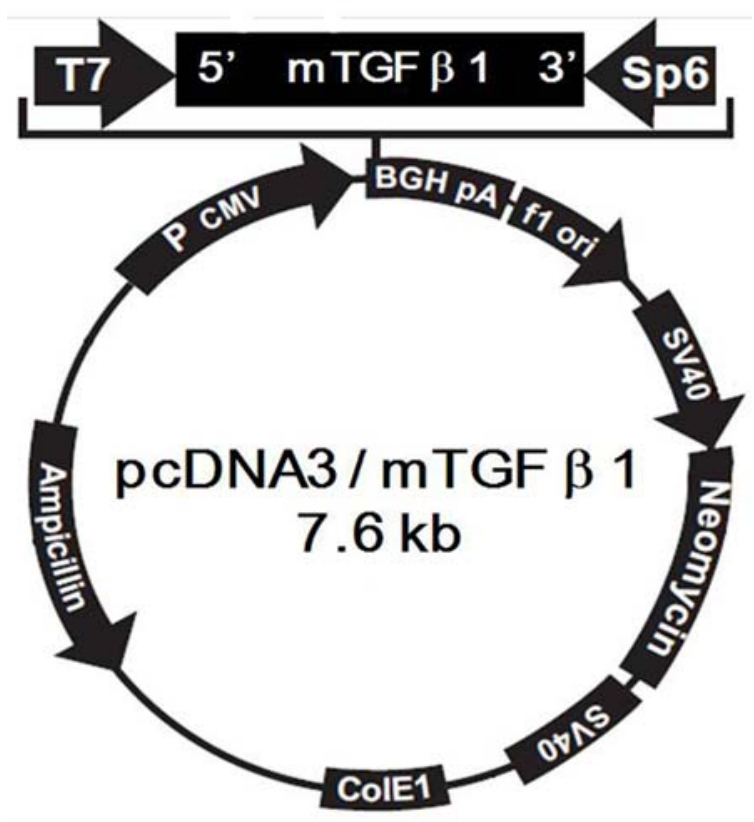

Fig. 1. The structure of plasmid TGF- $\beta 1$.

into the collagen/chitosan complex. Next, the scaffolds were lyophilised at $-80^{\circ} \mathrm{C}$ for $24 \mathrm{~h}$ before use.

\section{Scanning electron microscopy (SEM) analysis of 3D-NGDS}

The structural morphology of the scaffolds was examined by field-emission SEM (JEOL JSM5410, Tokyo, Japan). The pore size was estimated based on a minimum of 30 pores from different areas along the cross section of the scaffolds. Three scaffolds of each group and three different cross sections of each scaffold were used to estimate the pore size.

\section{In vitro release test of plasmid DNA from the 3D-NGDS}

The pDNA release test was performed according to a published report (Nie and Wang, 2007). Briefly, a $25 \mathrm{mg}$ 3D-NGDS sample was added to $5 \mathrm{~mL}$ PBS, $\mathrm{pH} 7.4$, which was the release medium in this experiment. The mixture was placed in an orbital shaker bath at $37^{\circ} \mathrm{C}$ and $120 \mathrm{rpm}$. A 1-mL sample was split from the release mixture after 24 $\mathrm{h}$ (day 1 ) and stored at $-20^{\circ} \mathrm{C}$ before DNA quantification. Before the release mixture was placed back in the shaker for further analysis, $1 \mathrm{~mL}$ fresh PBS was added to the release mixture to bring the total volume to $5 \mathrm{~mL}$. This procedure was repeated on day 3, day 6 , day 9 , day 12 and day 15 . In the two parallel studies, PBS containing $1 \mu \mathrm{g} / \mathrm{mL}$ chitosanase or $1 \mu \mathrm{g} / \mathrm{mL}$ collagenase was used as the release medium. The DNA concentrations of the release buffers were determined using a PicoGreen dsDNA Quantitation kit.

To mimic physiological conditions, additional pDNA release studies were performed in the cell culture medium, cell culture medium plus chitosanase, and cell culture medium plus collagenase, according to the same operation procedure as that described above. 


\section{Preparation and culture of mesenchymal stem cells (MSCs)}

MSCs were isolated from the femur shafts of 3-week-old male Wistar rats according to the technique reported by Lennon and Caplan (2006). Briefly, both ends of the rat femurs were cut away from the epiphyses and the bone marrow was flushed out by a syringe (21-gauge needle) with 1 mL Dulbecco's Modified Eagle's Medium(DMEM), supplemented with $10 \%$ foetal bovine serum (FBS) and $50 \mathrm{U} / \mathrm{mL}$ penicillin and streptomycin. The cell suspension (5 mL) was placed into two T-25 flasks (Iwaki Glass, Funabashi, Japan) and cultured at $37{ }^{\circ} \mathrm{C}$ in a $95 \%$ air, $5 \%$ $\mathrm{CO}_{2}$ atmosphere. The medium was changed on the fourth day of culture and every $3 \mathrm{~d}$ thereafter. When the cells of the first passage became subconfluent, which usually occurred 7-10 d after seeding, the cells were detached from the flask by being treated with PBS solution containing 0.25 $\%$ trypsin and $0.02 \%$ EDTA for 5 min at $37^{\circ} \mathrm{C}$. Cells were normally subcultured at a density of $2 \times 10^{6} \mathrm{cells} / \mathrm{cm}^{2}$. The cells of the second passage at subconfluence were used for all of the experiments.

\section{Cell seeding into the 3D-NGDS}

MSCs were seeded into the 3D-NGDS according to an agitated seeding method, which was effective in seeding cells homogenously into the porous $3 \mathrm{D}$ scaffolds. Briefly, $0.5 \mathrm{~mL}$ cell suspension $\left(2 \times 10^{6}\right.$ cells $\left./ \mathrm{mL}\right)$ and the scaffold were placed in $12 \mathrm{~mL}$ tubes (Iwaki Glass, Funabashi, Japan) on an orbital shaker (Bellco Glass, Vineland, NJ, USA) and agitated at $37^{\circ} \mathrm{C}$ and $300 \mathrm{rpm}$ for $6 \mathrm{~h}$. The MSCseeded scaffolds were thoroughly washed with calcium/ magnesium-free PBS to eliminate non-incorporated cells before the ensuing experiments.

\section{Transfection of MSCs with the 3D-NGDS}

MSCs were transfected conventionally by CP-pDNA-NPs or by the 3D-NGDS. Briefly, MSC cultures were prepared at a concentration of $2 \times 10^{6}$ cells $/ \mathrm{mL}$. For the conventional method, $0.5 \mathrm{~mL} \mathrm{MSC}$ cell cultures $\left(1 \times 10^{6}\right.$ cells $\left./ \mathrm{mL}\right)$ were plated into 24-well-plates (Corning Inc., Corning, NY, USA), and cultured at $37{ }^{\circ} \mathrm{C}$ with $5 \% \mathrm{CO}_{2}$ until $70 \%$ confluence was reached. Then $10 \mu \mathrm{g}$ CP-pDNA-NPs was added into each well and incubated with MSCs for $4 \mathrm{~h}$ before replacement with fresh medium. For the 3D-NGDS method, $0.5 \mathrm{~mL}$ MSCs $\left(1 \times 10^{6}\right.$ cells $\left./ \mathrm{mL}\right)$ was seeded into the 3D-NGDS (containing $10 \mu \mathrm{g}$ of CP-pDNA-NPs) according to the above-mentioned procedure. TGF- $\beta 1$ concentrations in the MSC culture medium were tested at day 3 and day 6 with a rat TGF- $\beta 1$ ELISA kit (USCN Life Science \& Technology, Missouri City, TX, USA). All experiments were repeated three times.

\section{Long-term transfection tests with the 3D-NGDS}

The long-term transfection efficiencies (up to $15 \mathrm{~d}$ ) of the 3D-NGDS were determined. MSC cultures were prepared at a concentration of $2 \times 10^{6}$ cells $/ \mathrm{mL}$. A 500 $\mu \mathrm{L}$ cell suspension $(100,000$ cells $)$ was added into each $3 \mathrm{D}-\mathrm{NGDS}$ and incubated in 24-well plates for $30 \mathrm{~min}$ to allow for cell attachment (day 0). Then, $1 \mathrm{~mL}$ of additional culture medium was added into each well, and the plates were incubated at $37{ }^{\circ} \mathrm{C}$ with $5 \% \mathrm{CO}_{2}$. After
$24 \mathrm{~h}, \mathrm{MSC}$-seeded 3D-NGDSs were transferred into new 24-well plates to eliminate cells that had attached to the polystyrene wells rather than the scaffolds. For comparison, the transfection efficiencies of free plasmid TGF- $\beta 1$ or plasmid TGF- $\beta 1$ plus $1 \mu \mathrm{g}$ Lipofectamine 2000 with FN in collagen/chitosan scaffolds were also determined. After transfections, the MSCs were further incubated for $15 \mathrm{~d}$. The cell culture media were replaced with fresh media on day 3, day 6, day 9, day 12 and day 15 , and the replaced media were collected and immediately frozen at $-80^{\circ} \mathrm{C}$ for determination of TGF- $\beta 1$ content. The TGF- $\beta 1$ levels in the MSC culture media were determined with a rat TGF- $\beta 1$ ELISA kit (USCN Life Science \& Technology, Missouri City, TX, USA). All experiments were repeated three times.

\section{Immunohistochemical analysis of MSCs cultured in the 3D-NGDS}

The MSCs cultured in the 3D-NGDS were washed with PBS and fixed in $10 \%$ neutral-buffered formalin before immunohistochemical analysis. Samples were dehydrated through a graded ethanol series, embedded in paraffin, and sectioned into $5 \mathrm{~mm}$ thick slices. For histological evaluation, sections were deparaffinised, rehydrated through a series of graded ethanol baths, and stained with toluidine blue ( $\mathrm{pH} 2.5)$. To identify cartilaginous ECM, sections were incubated with a rabbit anti-rat Col-II antibody (Santa Cruz Biotechnology, Santa Cruz, CA, USA) before being incubated with the horseradish peroxidase (HRP)-labeled secondary antibody (Boster, Wuhan, China).

\section{Determination of GAG content}

The GAG content of five groups was determined in this study, including free plasmid, Lipofectamine 2000, 3 D-NGDS, TGF- $\beta 1$ and TGF- $\beta 1$ plus Dex. Three days after transfection, the scaffolds were lyophilised for 24 $\mathrm{h}$ and digested in papain $(0.5 \mathrm{mg} / \mathrm{mL}$ in $50 \mathrm{mM}$ sodium phosphate, $1 \mathrm{mM}$ EDTA, $2 \mathrm{mM}$ DTT, $\mathrm{pH} 8.0$ at $65{ }^{\circ} \mathrm{C}$ ) for $24 \mathrm{~h}$ and subsequently diluted 10-100 times for the 1,9-dimethylmethylene blue (DMMB) colorimetric assay (Farndale et al., 1986). A GAG reference calibration curve was generated using a chondroitin-4-sulphate dilution (Sigma-Aldrich, St. Louis, MO, USA) dissolved in PBS at concentrations ranging from 10 to $100 \mu \mathrm{g} / \mathrm{mL}$. $10 \mu \mathrm{L}$ of each chondroitin-4-sulphate dilution was combined with $100 \mu \mathrm{L}$ DMMB solution in a 96-well plate. The absorbance at $520 \mathrm{~nm}$ was measured in each well using a plate reader (Beckman Coulter AD340, Fullerton, CA, USA). From the linear regression generated from the GAG calibration curve expressing absorbance at $520 \mathrm{~nm}$ as a function of chondroitin-4-sulphate concentration, the total GAG weight per milligram dry weight of scaffold was calculated. The same procedure was repeated on day 12 and day 21 .

\section{Determination of type I collagen expression}

The type I collagen expression level was determined in five groups: free plasmid, Lipofectamine 2000, 3D-NGDS, TGF- $\beta 1$ and TGF- $\beta 1$ plus Dex. The free plasmid group was used as the blank control. Three days after transfection, the culture medium was collected and tested with a competitive inhibition ELISA kit (Yantai Science and 
Table 1. Water uptake and retention abilities of collagen and chitosan scaffolds with different collagen/ chitosan weight ratios.

\begin{tabular}{|c|c|c|c|c|c|c|c|}
\hline $\begin{array}{c}\text { Collagen/ } \\
\text { Chitosan } \\
(\mathbf{w} / \mathbf{w})^{\mathbf{a}}\end{array}$ & 10:1 & $5: 1$ & $2: 1$ & $1: 1$ & $1: 2$ & 1:5 & 1:10 \\
\hline $\mathbf{R}_{\mathrm{ab}}^{\mathbf{b}}$ & $1850 \pm 2.98$ & $2130 \pm 1.55$ & $2304 \pm 1.49$ & $2559 \pm 1.90$ & $2604 \pm 2.11$ & $2933 \pm 1.02$ & $2990 \pm 1.60$ \\
\hline $\mathbf{R}_{\mathrm{ret}}{ }^{\mathbf{c}}$ & $1132 \pm 1.17$ & $1045 \pm 0.62$ & $980 \pm 0.77$ & $923 \pm 0.48$ & $872 \pm 0.63$ & $691 \pm 0.78$ & $653 \pm 1.12$ \\
\hline $\begin{array}{l}\text { Different w } \\
\text { Water absor } \\
\text { Water reten }\end{array}$ & $\begin{array}{l}\text { ht ratios of } \\
\text { on rate of } \\
n \text { rate of } \mathrm{sc}\end{array}$ & $\begin{array}{l}\text { collagen/chi } \\
\text { caffolds mea } \\
\text { ffolds meas }\end{array}$ & $\begin{array}{l}\text { san. } \\
\text { ured after } 24 \\
\text { ed after } 241\end{array}$ & $\begin{array}{l}h(n=5) \\
(n=5)\end{array}$ & & & \\
\hline
\end{tabular}

Biotechnology Co. Ltd., Shandong, China) according to the manufacturer's instruction. The same procedure was repeated on day 12 and day 21 .

\section{Statistical analysis}

Data were analysed by one or two-factor analysis of variance (ANOVA), Student's $t$-test and the Fisher's protected least-squares differences (FLSD) post hoc test to determine the significance (significance accepted at $p$ $<0.01$ ) of the difference between selected groups using SPSS statistic software (SPSS, Chicago, IL, USA). Data were presented as the mean \pm the standard error of the mean (SEM).

\section{Results}

Microstructures and physico-chemical properties of the collagen/chitosan scaffolds and the 3D-NGDS According to direct visual examination, the lyophilised 3D-NGDS samples were colourless, stiff and inelastic, while the hydrated and neutralised samples were soft, spongy, flexible and elastic.

To find the suitable weight ratio of collagen/chitosan in the 3D-NGDS preparation, collagen/chitosan scaffolds with various weight ratios were analysed by SEM and their representative microstructures are shown in Fig. 2. The scaffolds prepared with a 2:1 (collagen/chitosan) weight ratio were observed to have highly porous and interconnected pore structures (Fig. 2C) and good waterretention rates (Table 1). Thus, this 2:1 ratio was used in the following 3D-NGDS preparations. In the 3D-NGDS samples (Fig. 3C and 3D), the CP-pDNA-NPs were well coated on the collagen/chitosan scaffolds. Based on the quantitative SEM analysis, the pore sizes of the collagen/chitosan scaffolds (Fig. 3A) and 3D-NGDS samples (Fig. 3C) were both in the range of 50-100 $\mu \mathrm{m}$. Thus, the incorporation of CP-pDNA-NPs into collagen/ chitosan scaffolds did not change the scaffolds' ability to accommodate cells.

\section{Long-term release of plasmid DNA from the 3D-NGDS}

In vitro tests were performed to monitor the $\mathrm{pDNA}$ release from the 3D-NGDS. Chitosanase and collagenase were used to digest the collagen/chitosan scaffolds in the 3D-NGDS and guarantee the highest release of pDNA. The long-term release profiles of plasmid DNA in PBS and cell culture medium are shown in Figs. 4A and 4B, respectively. There was no obvious difference between these two release medium systems. In fact, pDNA seemed to have a linear release pattern both in PBS and cell culture medium until day 15 with or without chitosanase/collagenase. Even without any enzyme, more than $80 \%$ of the pDNA was released from the $3 \mathrm{D}-\mathrm{NGDS}$ by day 15 . These results suggest that pDNA could be released from the 3D-NGDS in a sustained and linear fashion, and the PBS release medium system could achieve almost the same effect as the cell culture medium for the in vitro release of pDNA.

\section{TGF- $\beta 1$ concentrations in MSC cultures transfected with the 3D-NGDS}

The TGF- $\beta 1$ concentration in MSC cultures were tested on day 3 and day 6 post transfection. Interestingly, the MSCs transfected with the 3D-NGDS showed remarkably high medium levels of TGF- $\beta 1$, exhibiting values of up to 12.3 $\mathrm{ng} / \mathrm{mL}$ and $12.6 \mathrm{ng} / \mathrm{mL}$ on day 3 and day 6 , respectively, (Fig. 5). Compared with those of cell cultures transfected by traditional methods, the TGF- $\beta 1$ concentrations were enhanced by fivefold on both day 3 and day 6 . The high TGF- $\beta 1$ concentration was probably caused by the highly efficient transfection of MSC cells in the 3D-NGDS.

\section{Long-term TGF- $\beta 1$ expression of MSCs transfected with the 3D-NGDS}

To study the long-term transfection efficiency of the 3D-NGDS, the MSCs were cultured for $15 \mathrm{~d}$ and the TGF- $\beta 1$ concentrations in the culture medium were recorded every three days. As shown in Fig. 6, for the MSCs transfected with the 3D-NGDS, the TGF- $\beta 1$ concentrations reached their peaks on day 6 , and then slowly declined to approximately $10 \mathrm{ng} / \mathrm{mL}$ by day 15 . In comparison, the TGF- $\beta 1$ concentrations of MSCs transfected by the Lipofectamine 2000 method in collagen/ chitosan scaffolds showed a more drastic drop after day 6. On day 15 , the TGF- $\beta 1$ concentrations of MSCs transfected with the 3D-NGDS were 6-fold higher than those of the Lipofectamine 2000 method. These results clearly demonstrate that the 3D-NGDS method imparted a significant improvement in the long-term transfection efficiency of TGF- $\beta 1$ in MSCs. 

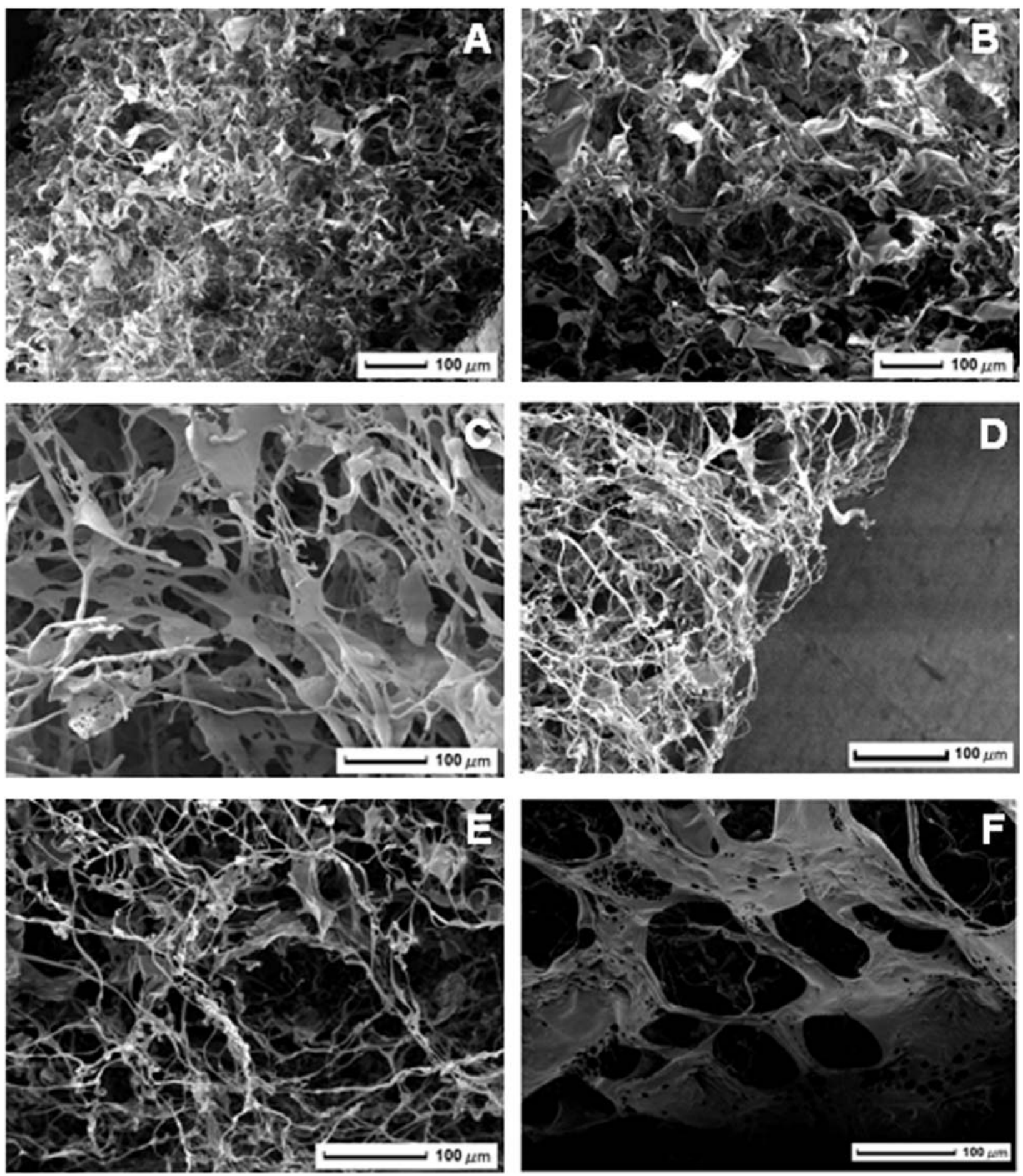

Fig. 2. SEM results of collagen/chitosan scaffolds prepared with different weight ratios of collagen/chitosan: 10:1 (A), 5:1 (B), 2:1 (C), 1:1 (D), 1:2 (E) and 1:5 (F).

Observation of collagen type II in the long-term cultured MSCs transfected with the 3D-NGDS It was observed that MSCs could be transformed into cartilaginous ECM in the presence of $10 \mathrm{ng} / \mathrm{mL}$ of exogenous TGF- $\beta 1$ protein. To confirm the transformation effect of the TGF- $\beta 1$ on MSCs transfected by different methods, an immunohistochemistry analysis for collagen type II was performed. The MSCs transfected by the 3D-NGDS method, Lipofectamine 2000 method or freeplasmid DNA were tested on day 9, day 12 and day 15. As shown in Fig. 7, the structures stained with DAB (brown) represented collagen type II. The MSCs transfected by the 3D-NGDS method showed the highest production of collagen type II between day 9 and day 15 (Figs. 7G7I), while a much lower production of collagen type II was observed in cells transfected by the Lipofectamine 2000 method. This finding suggests that the 3D-NGDS was more effective in the TGF- $\beta 1$-plasmid-induced MSC transformation compared with the conventional methods. 

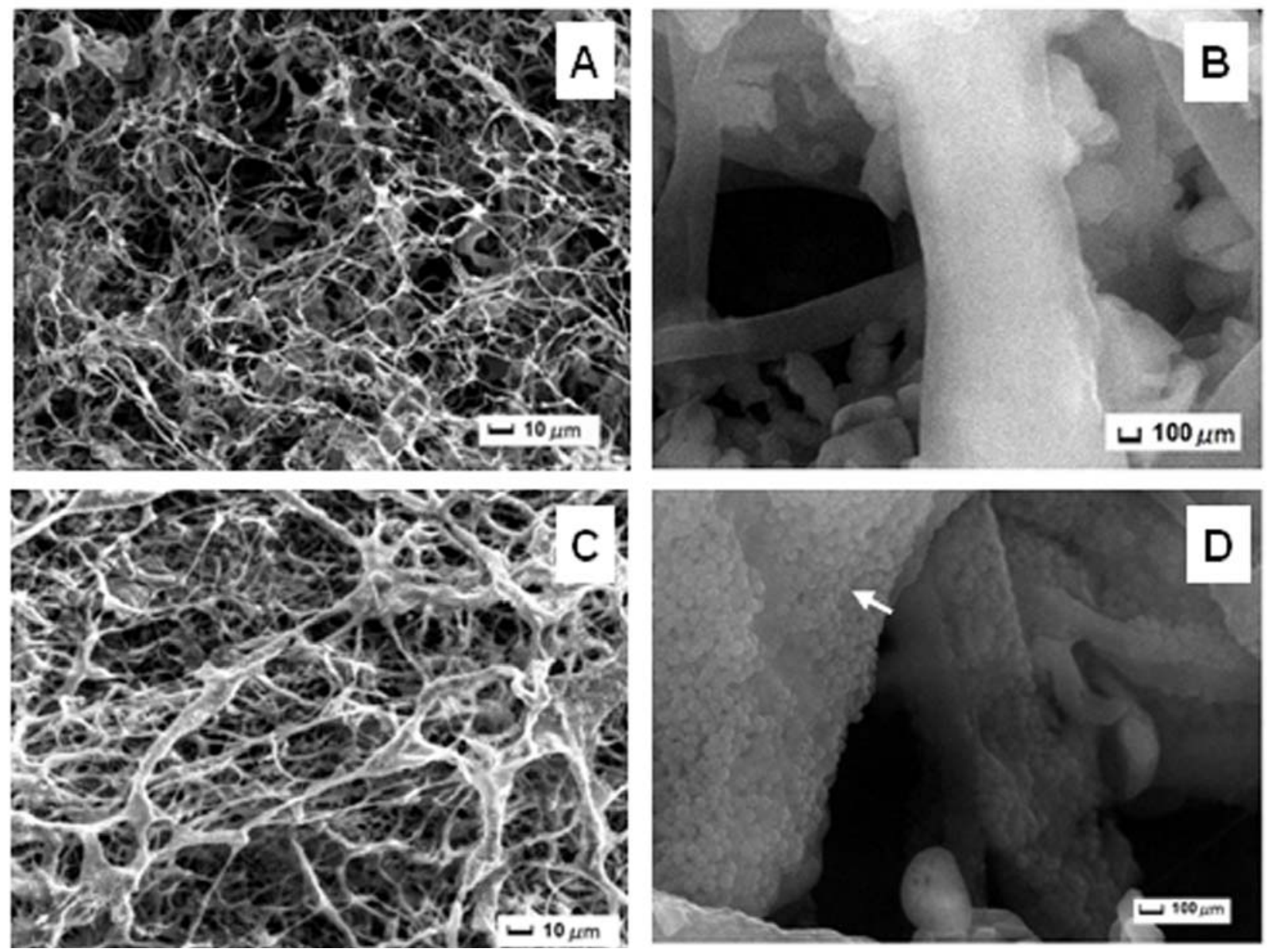

Fig. 3. SEM results of collagen/chitosan scaffolds (A and B) and the CP-pDNA-NP-incorporated 3D-NGDS (C and D). Two different magnifications are shown for each sample.

\section{GAG content}

The results of GAG content determination are shown in Fig. 8. Comparable GAG contents were observed between the 3D-NGDS group and TGF- $\beta 1$ group, as well as TGF- $\beta 1$ plus Dex group throughout the whole process, indicating the effective transfection and chondrogenic differentiation of the 3D-NGDS. However, there was a significant increase in the GAG content from day 12 to day 21 in the three groups: D-NGDS, TGF- $\beta 1$ and TGF- $\beta 1$ plus Dex $(p<$ 0.01 ). Interestingly, a remarkably higher GAG content ( $p$ $<0.01$ ) in the 3D-NGDS group was observed compared with that of the free-plasmid DNA and Lipofectamine 2000 groups on day 21, thereby indicating the superiority of the 3D-NGDS group with respect to gene delivery and efficient in vitro induction of chondrogenic differentiation of MSCs relative to both the free plasmid and Lipofectamine 2000 groups.

\section{Type I collagen expression}

The type I collagen expression rate was calculated using the concentration of type I collagen in the free-plasmid group as a standard, and the relative type I collagen expression levels of the other four groups were obtained by dividing by the standard level. As shown in Fig. 9, the type I collagen expression was suppressed in the tested groups
(Lipofectamine 2000, 3D-NGDS, TGF- $\beta 1$ and TGF- $\beta 1$ plus Dex) over time. The inhibitory effects on the type I collagen expression of the 3D-NGDS, TGF- $\beta 1$ and TGF- $\beta 1$ plus Dex were comparable throughout the whole process, which were much more pronounced than that observed for Lipofectamine 2000. Particularly, compared with that observed in the Lipofectamine 2000 group, a significant suppression of type I collagen expression was observed in the 3D-NGDS group on day $21(p<0.01)$.

\section{Discussion}

In this work, we selected natural, ECM-derived collagen to which appropriate amounts of chitosan and $\mathrm{FN}$ were added to construct a 3D nanoparticle gene delivery system. Figs. $2 \mathrm{~A}-2 \mathrm{~F}$ show the microstructure of the collagen/chitosan scaffolds with different collagen/chitosan weight ratios. The optimal porous structure of the collagen/chitosan blend scaffold that we prepared was at a collagen-tochitosan weight ratio of 2:1 (Fig. 2C). The result was a highly porous scaffold that was suitable for cell attachment and proliferation with a good water-retention rate and the ability to release plasmids in a sustained manner. After incorporating calcium phosphate nanoparticles, the pore 


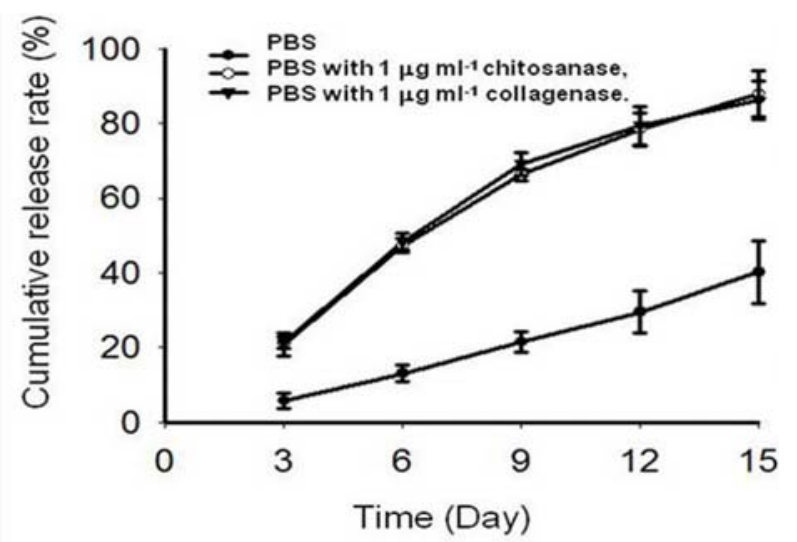

(a)

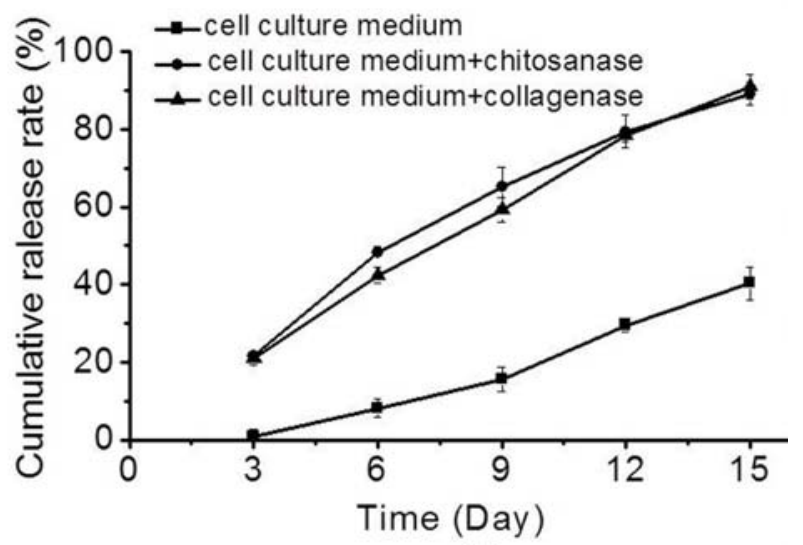

(b)

Fig. 4. Cumulative release rate of plasmid DNA from the 3D-NGDS. (A) Three release conditions were tested: PBS, PBS with $1 \mu \mathrm{g} / \mathrm{mL}$ chitosanase, and PBS with 1 $\mu \mathrm{g} / \mathrm{mL}$ collagenase; (B) three release conditions were tested: cell culture medium, cell culture medium with 1 $\mu \mathrm{g} / \mathrm{mL}$ chitosanase, and cell culture medium with $1 \mu \mathrm{g} /$ $\mathrm{mL}$ collagenase.

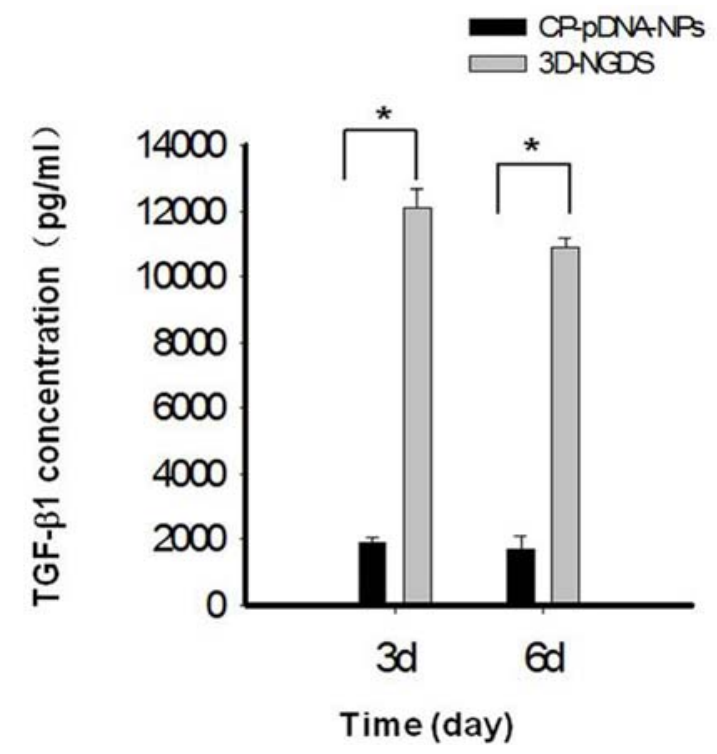

Fig. 5. TGF- $\beta 1$ concentrations in MSC culture medium. MSCs transfected with CP-pDNA-NPs or the 3D-NGDS were tested on day 3 and day 6 post-transfection. The TGF- $\beta 1$ concentrations from CP-pDNA-NPs are shown in black bars, and those from the 3D-NGDS are shown in grey bars $(*, p<0.01$ Student's $t$-test).

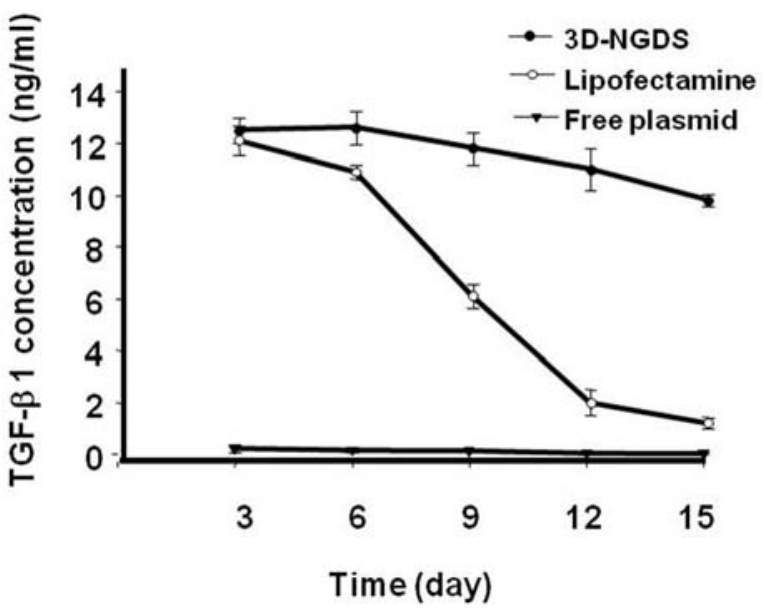

Fig. 6. Long-term TGF- $\beta 1$ expressions of MSCs transfected by the 3D-NGDS method, Lipofectamine 2000 method, or free plasmid. The TGF- $\beta 1$ concentrations were tested on day 3 , day 6 , day 9 , day 12 and day 15 (*, $p<0.01$, Student's $t$-test).

sizes of the collagen/chitosan scaffolds and 3D-NGDS samples, both of which were in the range of 50-100 $\mu \mathrm{m}$, did not change notably, as shown in Figs. 3A and 3C.

In this study, we innovatively used $\mathrm{FN}$ to connect calcium phosphate nanoparticles to the porous collagen/ chitosan scaffolds. FN is known as an adhesion molecule that is involved in many cellular processes including tissue repair, embryogenesis, blood clotting, and cell migration/ adhesion (Hattori and Maitani, 2007). FN can serve as a general cell adhesion molecule by anchoring cells to collagen or proteoglycan substrates as well as organising cellular interaction with the ECM by binding to different components of the extracellular matrix and to membranebound FN receptors on cell surfaces (Bingham and Potts, 2010).

The source of cells is another important component of tissue engineering strategy. MSCs are promising candidates for tissue engineering because of their easy isolation and proliferation, and their capacity to differentiate into many different kinds of cell lineages in vitro by providing appropriate factors (Yang et al., 2008; Wang et al., 2005) and to express transgenes efficiently (Yow et al., 2009). In our experiment, we chose MSCs to be seeded into the 3D-NGDS because of their excellent tissue-engineering properties. The 3D-NGDS was used to mimic the in vivo microenvironment required for cell proliferation and differentiation. This strategy therefore provided suitable conditions for the expression of plasmid TGF- $\beta 1$ in vitro, which contributed much to the remarkably high level of TGF- $\beta 1$ expression after transfection (up to $12.3 \mathrm{ng} / \mathrm{mL}$ and $12.6 \mathrm{ng} / \mathrm{mL}$ on day 3 and day 6, respectively) (Fig. 6). The samples displayed an enhanced TGF- $\beta 1$ expression level compared with those reported in a previous study, which employed a novel gene-modified tissueengineering approach for cartilage regeneration by using stable TGF- $\beta 1$-transfected MSCs seeded into chitosan scaffolds, resulting in an MSC-generated active TGF- $\beta 1$ concentration that was as low as $8 \mathrm{ng} / \mathrm{mL}$ on day 2 (Guo et 

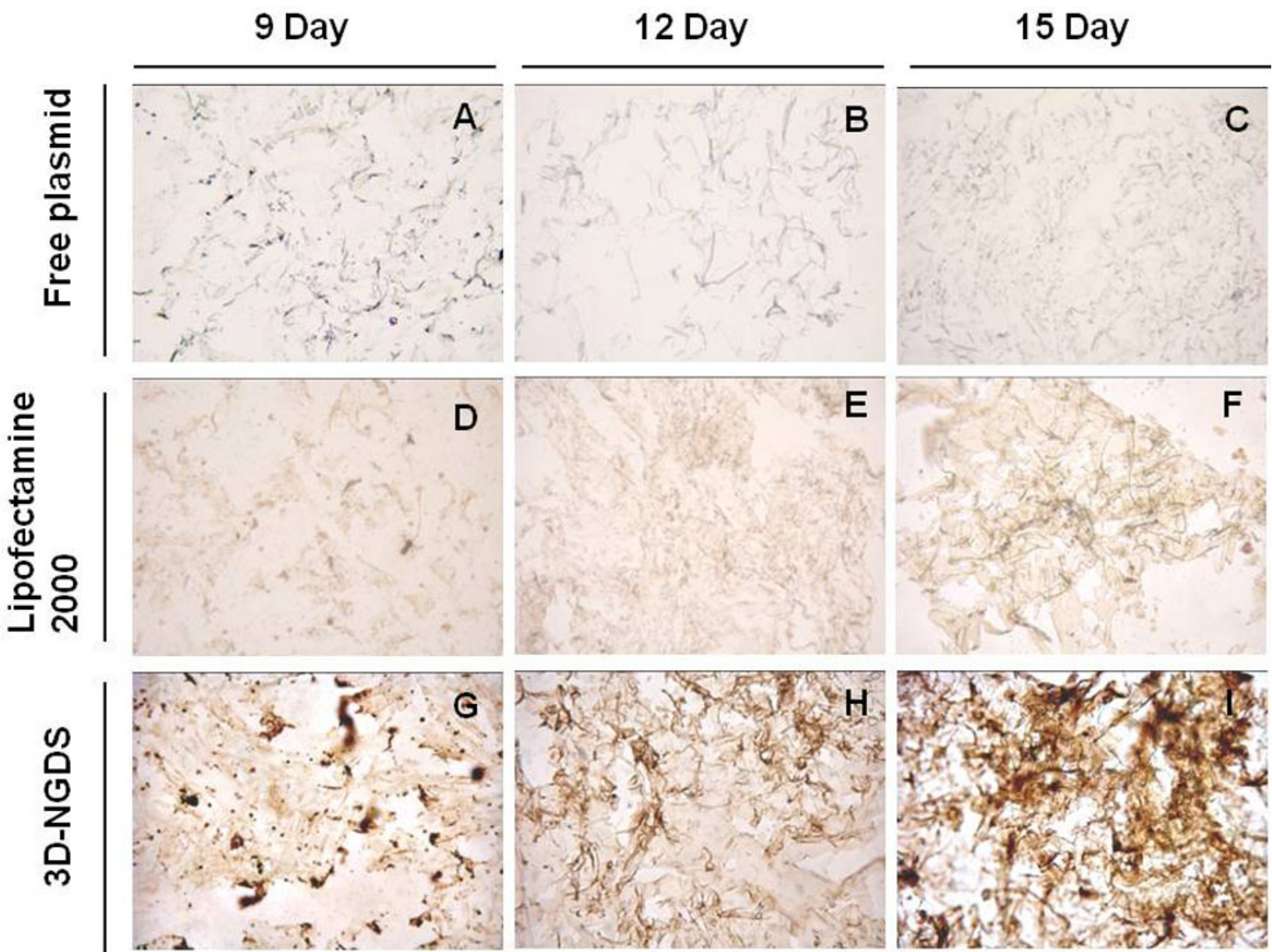

Fig. 7. Immunohistochemistry results of the MSCs transfected by different methods. The collagen type II synthesis by the MSCs was verified on day 9 (Panels A, D and $\mathbf{G}$ ), day 12 (Panels B, E and $\mathbf{H}$ ), and day 15 (Panels $\mathbf{C}, \mathbf{F}$ and I) post transfection. The MSCs transfected with free plasmid in collagen/chitosan scaffolds are shown in Panels A, B and C; the MSCs transfected with Lipofectamine 2000 in collagen/chitosan scaffolds (with FN) are shown in Panels D, E and F; the MSCs transfected with the 3D-NGDS method are shown in Panels $\mathbf{G}, \mathbf{H}$ and $\mathbf{I}$.

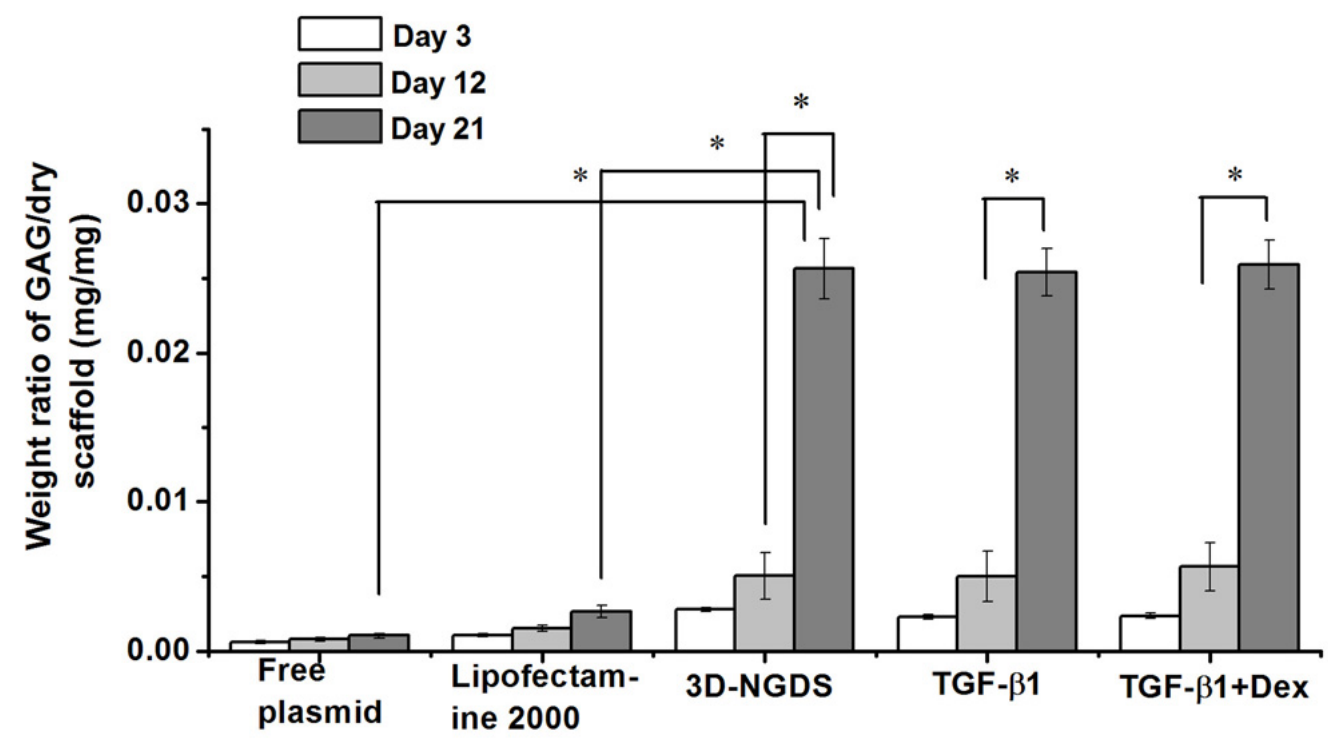

Fig. 8. GAG content in different groups: free plasmid, Lipofectamine $2000,3 D-N G D S, T G F-\beta 1$, and TGF- $\beta 1$ plus Dex on day 3,12 , and 21 (from left to right) $\left({ }^{*}, p<0.01\right.$, Student's $t$-test). 


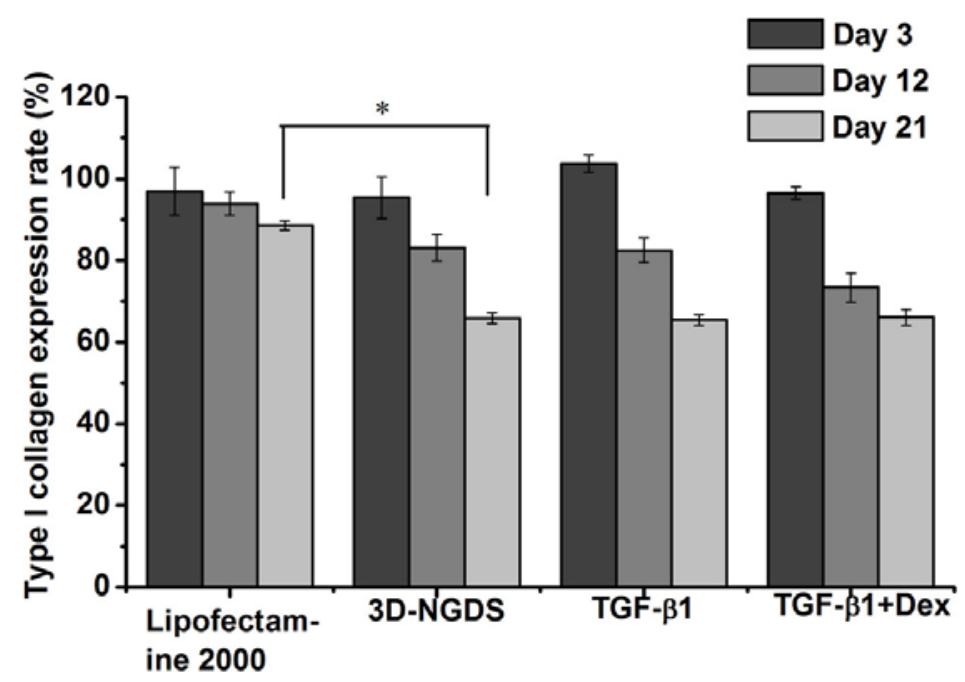

Fig. 9. The type I collagen expression rate of Lipofectamine 2000, 3D-NGDS, TGF- $\beta 1$, and TGF- $\beta 1$ plus Dex on day 3, 12, and 21 (from left to right) $(*, p<0.01$, Student's $t$-test).

$a l ., 2007)$. This finding is probably due to the fact that the 3D-NGDS possesses a highly porous structure with proper pore size and mechanical strength that provides a suitable microenvironment for MSC survival and differentiation, as well as the considerably large inner surface, which greatly enhances the opportunities for CP-pDNA-NP to contact and enter into MSCs. The elaboration of a more accurate mechanism would require further investigation in our future work.

One remarkable finding gathered from our present study is that the 3D-NGDS cannot only display a considerably high level of TGF- $\beta 1$ expression but also maintain a relatively long-term (15 d) sustained release of TGF- $\beta 1$, with a concentration of approximately $10 \mathrm{ng} / \mathrm{mL}$ on the 15 th day (Fig. 6). No burst release occured during the whole process after transfection. As shown in Fig. 6, the 3D-NGDS group clearly stimulated the cellular process compared with the pure collagen/chitosan free plasmid DNA and the Lipofectamine-seeded collagen/chitosan groups. It is interesting to note that in the Lipofectamineseeded collagen/chitosan group, a drastically reduced release of TGF- $\beta 1$ from approximately $11 \mathrm{ng} / \mathrm{mL}$ on the 6th day to less than $2 \mathrm{ng} / \mathrm{mL}$ on the 15 th day was observed, which was considerably lower than that of the 3D-NGDS during the same time course $(p<0.01)$. This result may be attributed to the fact that this 3D-NGDS degraded gradually over a relatively long time course ( $>15 \mathrm{~d})$. Fig. 4 shows that pDNA could be released from the 3D-NGDS in a sustained linear fashion with or without chitosanase/ collagenase. This result proves that this $3 \mathrm{D}-\mathrm{NGDS}$ was stable and immune to degrading enzymes, which make it suitable to be implanted into organs in vivo. The locally enhanced TGF- $\beta 1$ concentration in our experiment could act as an excellent driving force for the differentiation MSCs.

The turnover of the ECM is one of the most basic requirements for the adequate repair and regeneration of defective tissues. In this study, a series of studies including an immunohistochemistry analysis for type II collagen, GAG content determination and suppression of type I collagen expression were performed. As indicated in Fig. 7, the MSCs transfected by the 3D-NGDS method showed the highest production of type II collagen between the 9th and 15th day (Figs.7G-7I), while a much lower type II collagen content was observed in cells transfected by the Lipofectamine 2000 method. This finding suggests that TGF- $\beta 1$-transfected-MSCs seeded into the 3D-NGDS could successfully become an important component of chondrocyte extracellular matrices. Furthermore, the 3D-NGDS was more effective in facilitating the transformation of plasmid TGF- $\beta 1$-transfected MSCs compared with those of conventional methods. The significantly elevated GAG content of the 3D-NGDS compared with those of the free plasmid and Lipofectamine 2000 groups (Fig. 8) indicate the high efficacy of transfection and differentiation. Interestingly, the GAG content of the 3D-NGDS was comparable to the contents of the TGF- $\beta 1$ group and TGF- $\beta 1$ plus Dex group, indicating that a successful chondrogenic differentiation could be realised without Dex. This result suggests great progress in chondrogenic differentiation from MSCs. This finding was probably due to the fact that the $3 \mathrm{D}$ scaffold could provide an environment that mimics in vivo conditions for cell differentiation, which facilitated cell attachment. The results of the type I collagen inhibition study show that the type I collagen expression of the 3D-NGDS group, the TGF- $\beta 1$ group and the TGF- $\beta 1$ plus Dex group was markedly suppressed on day 21 . This finding provides further evidence for effective chondrogenic differentiation. In conclusion, MSCs incorporated with the 3D-NGDS could achieve successful chondrogenesis in vitro. Further in vivo investigations will be carried out in our future work to ascertain the tissue regeneration effect of the 3D-NGDS as the non-viral gene carrier. 


\section{Conclusions}

In this study, we constructed a 3D-NGDS to deliver plasmid TGF- $\beta 1$ into MSCs, resulting in the sustained release of TGF- $\beta 1$ with an elevated concentration for a relatively long time course compared with the results of previous studies (Barry et al., 2001; Guo et al., 2007). By comparing the sustained release of TGF- $\beta 1$ between the 3D-NGDS and Lipofectamine 2000 groups, our results show that this 3D-NGDS exhibited a higher TGF- $\beta 1$ expression level and sustained TGF- $\beta 1$ release, while the group transfected with Lipofectamine 2000 exhibited burst release by the 6 th day. Immunohistochemistry analysis revealed the clear expression of type II collagen. The GAG content of the 3D-NGDS, which was comparable to the contents of groups treated with TGF- $\beta 1$ as well as TGF- $\beta 1$ plus Dex, and the remarkable type I collagen expression inhibition of the 3D-NGDS, indicate that MSCs incorporated with the 3D-NGDS can achieve chondrogenic differentiation without Dex in vitro, thereby offering a notably promising alternative method of tissue regeneration.

\section{Acknowledgements}

This work was supported by National Natural Science Foundation of China (30772661 and 81072586), Special funds for 333 projects (BRA2010138) and industryuniversity-research institution cooperation (BY2009141) in Jiangsu Province. The authors also thank the University Ethics Committee for the kind guidance in the animal experiments.

\section{References}

Aviles MO, Lin CH, Zelivyanskaya M, Graham JG, Boehler RM, Messersmith PB, Shea LD (2010) The contribution of plasmid design and release to in vivo gene expression following delivery from cationic polymer modified scaffolds. Biomaterials 31: 1140-1147.

Barry F, Boynton RE, Liu B, Murphy JM (2001) Chondrogenic differentiation of mesenchymal stem cells from bone marrow: differentiation-dependent gene expression of matrix components. Exp Cell Res 268: 189200.

Bingham RJ, Potts JR (2010) Fibronectin structure: a new piece of the puzzle emerges. Structure 18: 660-661.

Bonadio J, Goldstein SA, Levy RJ (1998) Gene therapy for tissue repair and regeneration. Adv Drug Deliv Rev 33 53-69.

Bonadio J, Smiley E, Patil P, Goldstein S (1999) Localized, direct plasmid gene delivery in vivo: prolonged therapy results in reproducible tissue regeneration. Nat Med 5: 753-759.

Briganti E, Spiller D, Mirtelli C, Kull S, Counoupas C, Losi P, Senesi S, Stefano RD, Soldani G (2010) A composite fibrin-based scaffold for controlled delivery of bioactive pro-angiogenetic growth factors. J Control Release 142: 14-21.
Elisseeff J, McIntosh W, Fu K, Blunk BT, Langer R (2001) Controlled release of IGF-I and TGF-beta1 in a photopolymerizing hydrogel for cartilage tissue engineering. J Orthop Res 19: 1098-1104.

Fang J, Zhu YY, Smiley E, Bonadio J, Rouleau JP, Goldstein SA, McCauley LK, Davidson BL, Roessler BJ (1996) Stimulation of new bone formation by direct transfer of osteogenic plasmid genes. PNAS 93: 57535758.

Farndale RW, Buttle DJ, Barrett AJ (1986) Improved quantitation and discrimination of sulphated glycosaminoglycans by use of dimethylmethylene blue. Biochem Biophys Acta 883:173-177.

Garcia-Fuentes M, Meinel AJ, Hilbe M, Meinel L, Merkle HP (2009) Silk fibroin/hyaluronan scaffolds for human mesenchymal stem cell culture in tissue engineering. Biomaterials 30: 5068-5076.

Guo T, Zhao J, Chang J, Ding Z, Hong H, Chen J, Zhang J (2006) Porous chitosan-gelatin scaffold containing plasmid DNA encoding transforming growth factor-beta1 for chondrocytes proliferation. Biomaterials 27: 10951103.

Guo CA, Liu XG, Huo JZ, Jiang C, Wen XJ, Chen ZR (2007) Novel gene-modified-tissue engineering of cartilage using stable transforming growth factor- $\beta 1$-transfected mesenchymal stem cells grown on chitosan scaffolds. J Biosic Bioeng 103: 547-556.

Hafeman AE, Li B, Yoshii T, Zienkiewicz K, Davidson JM, Guelcher SA (2010) Injectable biodegradable polyurethane scaffolds with release of platelet-derived growth factor for tissue repair and regeneration. Pharm Res 25: 2387-2399.

Hang J, Zemskov EA, Lorand L, Belkin AM (2005) Identification of a novel recognition sequence for fibronectin within the NH2-terminal beta-sandwich domain of tissue transglutaminase. J Biol Chem 280: 23675-23683.

Hattori Y, Maitani Y (2007) DNA/Lipid complex incorporated with fibronectin to cell adhesion enhances transfection efficiency in prostate cancer cells and xenografts. Biol Pharm Bull 30: 603-607.

Hemmrich K, von Heimburg D, Rendchen R, Di Bartolo C, Milella E, Pallua N (2005) Implantation of preadipocyte-loaded hyaluronic acid-based scaffolds into nude mice to evaluate potential for soft tissue engineering. Biomaterials 26: 7025-7037.

Jang JH, Shea LD (2006) Intramuscular delivery of DNA releasing microspheres: microsphere properties and transgene expression. J Control Release 112: 120-128.

Jewell CM, Lynn DM (2008) Multilayered polyelectrolyte assemblies as platforms for the delivery of DNA and other nucleic acid-based therapeutics. Adv Drug Deliv Rev 60: 979-999.

Johnson PJ, Tatara A, Shiu A, Sakiyama-Elbert SE (2010) Controlled release of neurotrophin-3 and platelet-derived growth factor from fibrin scaffolds containing neural progenitor cells enhances survival and differentiation into neurons in a subacute model of SCI. Cell Transplant 19: 89-101.

Kanczler JM, Ginty PJ, Barry JJA, Clarke NMP, Howdle SM, Shakesheff KM, Oreffo ROC (2008) 
The effect of mesenchymal populations and vascular endothelial growth factor delivered from biodegradable polymer scaffolds on bone formation. Biomaterials 29: 1892-1900.

Kaspar M, Zardi L, Neri D (2006) Fibronectin as target for tumor therapy. Int J Cancer 118: 1331-1339.

Keeney M, van den Beucken JJJP, van der Kraan PM, Jansen JA, Pandit A (2010) The ability of a collagen/ calcium phosphate scaffold to act as its own vector for gene delivery and to promote bone formation via transfection with VEGF165. Biomaterials 31: 2893-2902.

Lee JE, Kim KE, Kwon IC, Ahn HJ, Lee SH, Cho H, Kim HJ, Seong SC, Lee MC (2004) Effects of the controlled-released TGF- $\beta 1$ from chitosan microspheres on chondrocytes cultured in a collagen/chitosan/ glycosaminoglycan scaffold. Biomaterials 25: 4163-4173.

Lennon DP, Caplan AI (2006) Isolation of rat marrowderived mesenchymal stem cells. Exp Hemato 34: 16061607.

Luu YK, Kim K, Hsiao BS, Chu B, Hadjiargyrou M (2003) Development of a nanostructured DNA delivery scaffold via electrospinning of PLGA and PLA-PEG block copolymers. J Control Release 89: 341-353.

Ma PX (2008) Biomimetic Materials for Tissue Engineering. Adv Drug Deliv Rev 60: 184-198.

Mao Z, Shi H, Guo R, Ma L, Gao C, Han C, Shen J (2009) Enhanced angiogenesis of porous collagen scaffolds by incorporation of TMC/DNA complexes encoding vascular endothelial growth factor. Acta Biomaterialia 5: 2983-2994.

Morgan TT, Muddana HS, Altinoglu EI, Rouse SM, Tabakovic A, Tabouillot T, Russin TJ, Shanmugavelandy SS, Butler PJ, Eklund PC, Yun JK, Kester M, Adair JH (2008) Encapsulation of organic molecules in calcium phosphate nanocomposite particles for intracellular imaging and drug delivery. Nano Lett 8: 4108-4115.

Nie H, Wang CH (2007) Fabrication and characterization of PLGA/HAp composite scaffolds for delivery of BMP-2 plasmid DNA. J Control Release 120: 111-121.

Peng L, Cheng XR, Wang JW, Xu DX, Wang G (2006) Preparation and evaluation of porous chitosan/collagen scaffolds for periodontal tissue engineering. J Bioact Compat Polym 21: 207-220.

Roohani-Esfahani SI, Nouri-Khorasani S, Lu Z, Appleyard R, Zreiqat H (2010) The influence hydroxyapatite nanoparticle shape and size on the properties of biphasic calcium phosphate scaffolds coated with hydroxyapatite-PCL composites. Biomaterials 31: 5498-5509.

Sachlos E, Czernuszka JT (2009) Making tissue engineering scaffolds work. Review on the application of solid freeform fabrication technology to the production of tissue engineering scaffolds. Eur Cells Mater 5: 29-40.

Samuel RE, Lee CR, Ghivizzani S, Evans CH, Yannas IV, Olsen BR, Spector M (2002) Delivery of plasmid DNA to articular chondrocytes via novel collagenglycosaminoglycan matrices. Hum Gene Ther 13: 791-802.

Saraf A, Baggett LS, Raphael RM, Kasper FK, Mikos AG (2010) Regulated non-viral gene delivery from coaxial electrospun fiber mesh scaffolds. J Control Release 143: 95-103.
Saul JM, Linnes MP, Ratner BD, Giachelli CM, Pun SH (2007) Delivery of non-viral gene carriers from sphere-templated fibrin scaffolds for sustained transgene expression. Biomaterials 28: 4705-4716.

Sottile J, Hocking DC, Langenbach KJ (2000) Fibronectin polymerization stimulates cell growth by RGD-dependent and-independent mechanisms. J Cell Sci 113: 4287-4299.

Suh JKF, Matthew HWT (2000) Application of chitosan-based polysaccharide biomaterials in cartilage tissue engineering: a review. Biomaterials 21: 2589-2598.

Sun XD, Jeng L, Bolliet C, Olsen BR, Spector M (2009) Non-viral endostatin plasmid transfection of mesenchymal stem cells via collagen scaffolds. Biomaterials 30: 12221231.

Tan W, Krishnaraj R, Desai TA (2001) Evaluation of nanostructured composite collagen-chitosan matrices for tissue engineering. Tissue Eng 7: 203-210.

Tang XJ, Wu QY (2006) Mesenchymal stem cellular adhesion and cytotoxicity study of random biopolyester scaffolds for tissue engineering. J Mater Sci: Mater Med 17: 627-632.

Wang Y, Kim UJ, Blasioli DJ, Kim HJ, Kaplan DL (2005) In vitro cartilage tissue engineering with 3D porous aqueous-derived silk scaffolds and mesenchymal stem cells. Biomaterials 26: 7082-7094.

Wang X, Wenk E, Zhang X, Meinel L, VunjakNovakovic G, Kaplan DL (2009) Growth factor gradients via microsphere delivery in biopolymer scaffolds for osteochondral tissue engineering. J Control Release 134: 81-90.

Xu XM, Capito RM, Spector M (2008a) Delivery of plasmid IGF-1 to chondrocytes via cationized gelatin nanoparticles. J Biomed Mater Res A 84: 73-83.

Xu XM, Capito RM, Spector M (2008b) Plasmid size influences chitosan nanoparticle mediated gene transfer to chondrocytes. J Biomed Mater Res A 84: 1038-1048.

Yang Q, Peng J, Guo Q, Huang J, Zhang L, Yao J, Yang F, Wang S, Xu W, Wang A, Lu S (2008) A cartilage ECM-derived 3-D porous acellular matrix scaffold for in vivo cartilage tissue engineering with $\mathrm{PKH} 26$-labeled chondrogenic bone marrow-derived mesenchymal stem cells. Biomaterials 29: 2378-2387.

Yow SZ, Quek CH, Yim EKF, Lim CT, Leong KW (2009) Collagen-based fibrous scaffold for spatial organization of encapsulated and seeded human mesenchymal stem cells. Biomaterials 30: 1133-1142.

Zhang Y, Cheng X, Wang J, Wang Y, Shi B, Huang C, Yang X, Liu T (2006) Novel chitosan/collagen scaffold containing transforming growth factor- $\beta 1$ DNA for periodontal tissue engineering. Biochem Biophys Res Commun 344: 362-369.

\section{Discussion with Reviewer}

Reviewer I: TGF- $\beta 1$ is known to bind to both collagen and fibronectin. Therefore, measurements of TGF- $\beta 1$ in the medium over extended timeframes may represent not only long term transfection, but also sustained TGF- $\beta 1$ release from scaffolds, which would have affinity for the growth 
factor. It is noteworthy that this type of phenomenon may be operative in many other similar studies, as many common biomaterials used as tissue engineering scaffolds have high affinity for proteins. Examples include calcium phosphate minerals, collagen, several polysaccharides (e.g. heparin), and most ECM proteins.

Authors: As described in the section on "Preparation of the 3-dimensional nanoparticle gene delivery system", CP-pDNA-NPs (calcium phosphate nanoparticles encapsulating plasmid TGF- $\beta 1$ ) were incorporated into the scaffold. Thus, it was likely that the sustained release of CP-pDNA-NPs from the scaffold resulted in the longterm sustained transfection of the cells, leading to the long-term presence of TGF- $\beta 1$. Because TGF- $\beta 1$ could bind to collagen and/or fibronectin, TGF- $\beta 1$ sequestration may possibly contribute to the long-term release. The exact mechanism of this phenomenon will be investigated in our future work. 